\title{
JORS part special issue OR42 papers: an editorial overview
}

\author{
B Lehaney ${ }^{1 *}, \mathrm{~S} \mathrm{Clarke}^{1}$ and $\mathrm{M}$ Nicholls ${ }^{2}$ \\ ${ }^{1}$ Luton University, UK; and ${ }^{2}$ Swinburne University, Victoria, Australia
}

We are very pleased to have been able to edit a part special issue of JORS based on papers from OR42, the Operational Research Society Annual Conference, held from 12-14th September 2000, in Swansea. The papers selected for publication very much represent the theme of the conference, which was 'Operational Research in the Twenty First Century: Communications and Knowledge Management'.

It is particularly pleasing to finally go to print, because at the time of the conference, there were major transport disruptions caused by petrol protests around the country. No petrol could be found in or around Swansea-or anywhere else in the country. The committee feared that attendance would be affected, but, in the end, over 260 delegates appeared, and there was an excellent range of presentations and plenary papers.

Presenters were all given the opportunity to submit papers to any publications of the ORS, but, in particular, three members of the committee were given the task of creating a special issue of JORS. Of the papers submitted, four were finally selected for publication after the refereeing process.

Davies and Mabin' discuss 'Knowledge Management and the Framing of Information'. Within this paper the authors consider how knowledge is created, diffused and used. They argue that understanding these issues can help provide a means to pluralistic insights, and therefore knowledge. Various 'frames' are considered, and the paper finally puts forward the case that this approach may be viable for teaching OR/MS and enhancing knowledge management.

Dhir' ${ }^{2}$ addresses a 'Judgement Analytic Approach to Understanding Models'. In this paper the author considers the gap between management's understanding of a model and the model builder's insight. The paper discusses how judgements and sources of disagreements may be surfaced and identified and how, subsequently, judgements may be changed in the light of new information. The author provides an illustrative example of how soft and hard approaches may be used in a given problem context.

Leal de Matos $^{3}$ discusses 'Yield Management (YM) for Privatised Air traffic Control (ATC)'. In this paper the author considers how applicable YM policies are to European ATC. This is of interest because ATC ensures the safety and timeliness of aircraft in controlled airspace, which is normally around 2000 metres above main airports. With air traffic congestion on the increase and with privatization, ATC must now not only be effective, but cost efficient as well.

Pavur and Loucopoulos ${ }^{4}$ report on 'Evaluating the effect of Gap Size in a Single Function Mathematical Programming Model for the Three-Group Classification Problem'. The authors argue that the discriminant score of an observation may fall into the gap between adjacent group intervals in cases where mathematical programming based models project discriminant scores onto a line. A theoretical assessment and a Monte Carlo simulation are used to determine impacts.

We hope that those of you who attended enjoyed OR42, and we also hope that you will enjoy reading this small selection of papers.

\section{References}

1 Davies J and Mabin VJ (2001). Knowledge management and the framing of information: a contribution to OR/MS practice and pedagogy. J Opl Res Soc 52: 856-872.

2 Dhir KS (2001). Enhancing management's understanding of operational research models. J Opl Res Soc 52: 873-887.

3 Leal de Matos PL (2001). Yield Management for privatised air traffic control. J Opl Res Soc 52: 888-895.

4 Pavur R and Loucopoulos (2001). Evaluating the effect of gap size in a single function mathematical programming model for the three group classification problem. J Opl Res Soc 52: 896904. 